\title{
URANIUM-SERIES AGES OF CORALS, SEA LEVEL HISTORY, AND PALAEOZOOGEOGRAPHY, CANARY ISLANDS, SPAIN: AN EXPLORATORY STUDY FOR TWO QUATERNARY INTERGLACIAL PERIODS
}

\author{
Muhs, Daniel R ${ }^{\mathrm{a}}$; Meco, J. ${ }^{\mathrm{b}}$; Simmons, Kathleen $\mathrm{R}^{\mathrm{c}}$
}

a U.S. Geological Survey, Federal Center, MS 980, Box 25046, Denver, CO 80225, United States

b Departamento de Biología, Universidad de Las Palmas de Gran Canaria, 35017 Las Palmas, Canary Islands, Spain

c U.S. Geological Survey, Federal Center, MS 963, Box 25046, Denver, CO 80225, United States

\begin{abstract}
We present the first U-series ages of corals from emergent marine deposits on the Canary Islands. Deposits at $+.20 . \mathrm{m}$ are $481 \pm 39 \mathrm{ka}$, possibly correlative to marine isotope stage (or MIS) 11 , while those at +.12 and $+.8 . \mathrm{m}$ are $120.5 \pm 0.8$. ka and $130.2 \pm 0.8$. ka, respectively, correlative to MIS 5.5. The age, elevations, and uplift rates derived from MIS 5.5 deposits on the Canary Islands allow calculations of hypothetical palaeo-sea levels during the MIS 11 high sea stand. Estimates indicate that the MIS 11 high sea stand likely was at least +. 9. $\mathrm{m}$ (relative to present sea level) and could have been as high as +.24 . $\mathrm{m}$. The most conservative estimates of palaeo-sea level during MIS 11 would require an ice mass loss equivalent to all of the modern Greenland and West Antarctic ice sheets; the more extreme estimates would require additional ice mass loss from the East Antarctic ice sheet. Extralimital southern species of mollusks, found in both MIS 11 and MIS 5.5 deposits on the Canary Islands, imply warmer-than-modern sea surface temperatures during at least a part of MIS 11 and much warmer sea surface temperatures during at least a part of MIS 5.5. Both MIS 11 and MIS 5.5 marine deposits on the Canary Islands contain extralimital northern species of mollusks as well, indicating cooler-thanpresent waters at times during these interglacial periods. We hypothesize that the cooccurrence of extralimital southern and northern species of marine invertebrates in the fossil record of the Canary Islands reflects its geographic location with respect to major synoptic-scale controls on climate and ocean currents. Previous interglacials may have been characterized by early, insolation-forced warming, along with northward migration of the intertropical convergence zone (ITCZ), accompanied by weakened trade winds and diminished upwelling. This allowed the arrival of extralimital southern taxa from the tropical Senegalese faunal province. During later parts of the MIS 11 and 5.5 interglacials, decreased insolation may have resulted in southward migration of the ITCZ, strengthened trade winds, and re-establishment of upwelling. Such conditions may have brought about not only local extinction of the Senegalese fauna, but allowed southward migration of the cooler-water Mediterranean fauna to the Canary Islands in the later parts of interglacials, a complex palaeoclimate record that is mirrored in the deep-sea core record.
\end{abstract}

